B Research S Suare

\title{
Maintenance Preventive Analysis in Additive Manufacturing Equipment using Analytic Hierarchy Process
}

Pablo Ayala ( $\sim$ payala@itcj.edu.mx )

Instituto Tecnologico de Ciudad Juarez https://orcid.org/0000-0002-0045-2395

Hugo Francisco López Herrera

Instituto Tecnológico de Ciudad Juárez: Instituto Tecnologico de Ciudad Juarez

\section{Research Article}

Keywords: MCDM, AHP, EQUIPMENT, PM, CRI, MANUFACTING SYSTEM, DECISION MAKING Introduction

Posted Date: November 30th, 2021

DOI: https://doi.org/10.21203/rs.3.rs-1047953/v1

License: (c) (i) This work is licensed under a Creative Commons Attribution 4.0 International License.

Read Full License 


\title{
Maintenance Preventive Analysis in Additive Manufacturing Equipment using Analytic Hierarchy Process
}

\author{
Pablo Ayala Hernández ${ }^{1}$, Hugo Francisco López Herrera ${ }^{2}$
}

\begin{abstract}
Maintenance preventive (PM) on equipment is a very important issue for an effective manufacturing system, since the improper MP might cause many problems affecting productivity, precision, flexibility and quality of the products negatively. On the other hand, analysis of MP equipment among many alternatives can be a multicriteria decision making (MCDM) problem. In this study, an integrated approach which employs analytic hierarchy process (AHP) and preference ranking elements, is proposed for the MP equipment of 3D printer machine. The AHP is used to analyze the structure of the equipment problems and to determine weights of the criteria, and this method is used to obtain final ranking. Proposed approach is applied to a problem of 3D printer machines to be established a MP strategy.
\end{abstract}

\section{Keywords: MCDM, AHP, EQUIPMENT, PM, CRI, MANUFACTING SYSTEM, DECISION MAKING}

\section{Introduction}

A proper equipment preventive maintenance (PM) is a very important activity for manufacturing systems, due to the fact that the lack of PM can negatively affect the overall performance and productivity of a manufacturing system. The outputs of manufacturing system (i.e., the rate, quality and cost) mostly depend on what kinds of properly PM is used (Ayag and Ozdemir 2006, Alsyouf, 2004).

In addition to this, PM has a major effect on the companies' global competitiveness. Using in proper manufacturing equipment PM can enhance the production process, provide effective utilization of machines, increase production, and improve system flexibility. However, with the wide range of equipment available today, determination of the best equipment alternative for a given production scenario is not an easy task (Chan et al. 2001, Pariazar et al. 2008).

Although PM plays an important role in the design of an effective manufacturing preventive system, the publications on this subject are limited (Kulak et al. 2005, Fraser et al. 2015). The studies performed could be classified into one group as machine selection. One of the recent studies is by Standing et al. (2001) which uses multi-attribute utility theory to quantify the contribution of various structural and infrastructural factors for an equipment PM decision. Tabucanon et al. (1994) developed a decision support system for multi-criteria machine PM problem for flexible

\footnotetext{
${ }^{1}$ Department of Graduate School, Tecnológico Nacional de México campus Ciudad Juárez, Instituto Tecnológico de Ciudad Juárez, Ciudad Juárez, México. Corresponding principal author email address: payala@itcj.edu.mx

${ }^{2}$ Department of Graduate School, Tecnológico Nacional de México campus Ciudad Juárez. Instituto

Tecnológico de Ciudad Juárez, Ciudad Juárez, México. Author email address: hantiques50@hotmail.com
} 
manufacturing systems (FMS), and used the analytic hierarchy process (AHP) technique for the machine selection.

Chen (1999) develops an integer programming model and a heuristic algorithm to solve the problem of multiple time periods.

Machine maintenance preventive from fixed number of available machines is also considered by Atmani and Lashkari (1998), who developed a model for machine PM and operation allocation in FMS. Lin and Yang (1996) proposed AHP for machine PM problem. Yurdakul (2004) applied AHP and ANP (Analytic Network Process) for calculation of the contributions of machine tool alternatives to the manufacturing PM strategy of a manufacturing organization.

In addition, the articles for equipment PM decisions are presented by Oeltjenbruns et al. (1995) and Sullivan et al. (2002). In the equipment PM problem, there are a finite number of alternatives which have to be ranked considering many different and conflicting criteria. Accordingly, this problem is considered as a multi-criteria decision-making (MCDM) problem. Several methods exist for MCDM (Zeleny 198, Vincke 1992, Ho et al. 2006). There are no better or worse techniques, but some techniques better suit to particular decision problems than others do (Mergias et al. 2007). The advantage of these methods is that they can account for both financial and non-financial impacts.

Among these methods, the most popular ones are scoring models (Nelson 1986), analytic hierarchy process (AHP) (Ong et al. 2001).

The MCDM method choice decision should wait until the analyst and the decision makers understand the problem, the feasible alternatives, different outcomes, conflicts between the criteria and level of the data uncertainty (Mergias et al. 2007, Shafiee, M. (2015). Multi-criteria decision making (MCDM) methods such as AHP and Fuzzy AHP, used for equipment PM problems in the literature, make the evaluations using the same evaluation scale and preference functions on the criteria basis.

In this paper, AHP approach for selection of the most suitable PM equipment will be introduced and the implementation process will be explained with a theorical example. We shall use the AHP method to analyze the structure of the equipment selection problem and determine the weights of criteria, In the application, the criteria, which have the greatest effect on the equipment PM are determined via a sensitivity analysis, moreover how the ranking changes if the criteria did not have weights will be analyzed.

Being the contribution of this paper, presenting a methodology that allows to predict on additive manufacturing equipment PM using a AHP method by Saaty (1980), with the research aims to: (a) propose a Multi-Criteria Decision Making (MCDM) methodology to obtain the PM principal elements at 3D machine printer; (b) propose a weighting calculation alternative that incorporates the acquired knowledge in the research found in the literature review and experts judgment used in AHP; (c) presenting a theorical research model that shows the hierarchical factors, as well as their corresponding scoring values, that can be used to establish concrete strategies for each factor. 
The following research questions are addressed:

1. How can the AHP be used to identify the relevant PM elements in 3D machine printer?

2. How is it possible to use an equation to calculate the weighting values for each criterion incorporating the acquired knowledge and the expert judgment evaluation?

3. Can the results obtained be considered reliable and aligned to other ways to calculate weighting values?

In this manner, the AHP is using criteria weight methodology proposed in this research will be evaluated under the hypothesis:

"The weighting values for each criterion based on acquired knowledge of AHP, provides CRI coefficient lower than 0.10 used Saaty method."

This paper is divided into six sections.

1. Introduction, the studied problem is introduced.

2. Principles of AHP describes the proposed methodology.

3. Proposed AHP approach.

4. A theorical application of proposed AHP approach.

5. Result.

6. Conclusion.

\section{Relevant literature review}

The section is divided into three sub-sections: review related to equipments, MCDM methods, gap identification with respect to additive manufacturing equipment PM.

\section{Critical Equipments}

The equipments, whose running is very much required for the process to continue, are called critical equipments. These are critical not only from operation point of view but from maintenance point of view as well. With increased competitive environment and opening of the power sector to the private players, cheap and continuous power supply is going to become the catch word of power business. To have edge over the others, one has to have a very high plant uptime at low cost. For this, proper maintenance activities are the only answer. To achieve this, we need to prioritize the maintenance activities as per the criticality of the equipments. A large number of researchers have used different approaches to have these equipments identified. Zhaoyang et al. 2011, Bevilacqua, M. and Braglia, M. 2000) have used a risk-based inspection methodology to categorized the equipments. Srikrishna et al. (1996) have used some criteria like: generation loss, maintenance cost, availability, MTBF to carry out criticality analysis of equipments of a power-plant. Pascual et al. (2011) have used a technique called System Efficiency Influence Diagram (SEID) for prioritizing equipments for maintenance action. Carazas et al. (2010) have used concepts related to risk to identify critical equipments. The authors have used a risk-based method for selection of maintenance policy for critical equipments. Identification of critical equipments is not an easy task as it deals with multiple criteria. Hence, we have to use multi criteria decision making processes to 
arrive at a decision. The next sub-section is devoted to a brief literature review of some MCDM methods.

\section{MCDM Methods}

Decision making was there from the very beginning of evolution of Homo-sapiens. One makes decision in day today life. But changing business dynamics has made it imperative on a decision maker to have a quantified decision. With increasing complexity of problems, one has to face a problem which has many alternatives and the no of criteria are also more than one. In these situations, use of MCDM methods is the only answer. In all the MCDM methods, the main goal is to select the best alternative or to rank a set of given alternatives (Chatterjee et al., 2012, Peters, M. and Zelewski, S.; 2008). Generally, in a MCDM process the main steps: Saaty (1980), Yang et.al. (2009), Wu et. al. (2007), De Almeida, A. T., \& Bohoris, G. A. (1995). are:

1. Establishing system evaluation criteria that relate system capability to goals;

2. Developing alternative systems for attaining the goals;

3. Evaluating alternatives in terms of criteria;

4. Applying a normative multi-criteria analysis method;

5. Accepting one alternative as optimal or preferred;

6. If the final solution is not accepted, gather new information and go into the next iteration of multi-criteria optimization.

Multiple criteria decision-making (MCDM) methods provide an efficient means of assisting decisionmakers to choose the best alternative under different criteria. Some tools and standard operational processes are used to assist the decision-maker to achieve the goal of a systematized solution. Over the last few years, a large number of methods have been developed for multi criteria decision making.

AHP (Analytic Hierarchy Process) is one of the very popular and widely used MCDM methods. It assumes that a problem can be structured as a hierarchy of an overall goal and a set of conflicting information. In this a typical decision problem is structured in three levels. The goal is at the top level of the AHP decision hierarchy, while the criteria are placed on the second level. These criteria are used to judge the alternatives on the lowest level. These are used to evaluate a predetermined number of alternatives. All the elements in a particular cluster of the hierarchy are compared in a pair wise sub goals that may require quantitative and qualitative fashion with respect to their contribution or importance for the root of the cluster (Saaty, 1990, Petkov et.al.,2007, Peters et al., 2008). It is being used in a variety of applications. Zhaoyang et al. (2011), Al-Najjar, B. and Alsyouf I. (2003), have used this method to select the most practicable maintenance strategy for equipments. Caputo et al. (2013), Bertolini, M. and Bevilacqua, M. (2006) have found it useful for selection of safety devices for industrial machinery. Molenaers et al. (2012, Salonen, A. (2011) have used AHP to solve multi-criteria sub problem at different decision nodes. Goh et al. (2013) have used AHP and TOPSIS for load shedding operations of a large pulp mill. They have ranked load according to their importance for load shedding purposes. In many applications, AHP is used to find out weight for all the criteria and then some other method is used for the final analysis. Chan et al. (2001, Chan et al. (2007) have applied AHP to find out weight for different criteria for their analysis by expert system. One of the reasons of popularity of AHP is that it is good in dealing with both tangible as well as intangible attributes (Chatterjee et al., 2011, Lerace, S. and Cavalieri, S. (2008). 


\section{Identified Gap from the Literature Reviewed}

A large number of literatures were surveyed, but couldn't found a lot literature which discusses additive manufacturing equipments maintenance preventive using AHP.

\section{The AHP method}

One of the most popular Multi-criteria Decision Analysis (MCDA) methods is the analytic hierarchy process (AHP), proposed and developed by Saaty (1980). AHP helps decision-makers by providing them with a structure to effectively compare the competing alternatives (Handfield et al., 2002, Kutucuoglu et al. (2001). AHP uses a method of pair-wise comparison for decisions with several criteria (Huang et al., 2011, Saaty, (1994). AHP compares alternatives based on their performance in each criterion as well as decision-makers' preferences over those criteria (Lee et al. 2011, Kablan M. M. (2004). Decision-makers often express their preferences by assigning weights to criteria.

Analytic Hierarchy Process (AHP) is a method to select one alternative from a given set of alternatives, where there are multiple decision criteria involved, and to rank available alternatives in a desirability order based on a rational framework of quantitative comparisons (Saaty, 1990). AHP is basically built on a solid yet simple theoretical foundation based on three basic principles (Saaty, 1990):

1. Decomposition;

2. Comparative judgments; and

3. Hierarchy composition.

AHP builds hierarchies starting from the proposed problem as the base and moving up to criteria and alternatives as the upper levels (Saaty, 1980). This hierarchy system simplifies various objectives and goals into a single score and chooses the alternative with highest score for the decision-makers. The comparison matrix is based on a quantified scale and comparative scores are entered in a judgmental matrix that facilitates calculation and aggregation of weights (Kabir et al., 2013, Saaty, 1980). All weights are then normalized by dividing geometric mean of each criterion by sum of geometric means of all criteria (Linkov et al., 2004, Fouladgar et al. 2012). AHP has advantage of generating inconsistency number relative to decision-maker's inconsistency number (Pohekar and Ramachandran, 2004, Saaty, 2006). The AHP method is based on three principles: first, structure of the model; second, comparative judgment of the alternatives and the criteria; third, synthesis of the priorities.

The first step, a complex decision problem is structured as a hierarchy. AHP initially breaks down a complex MCDM problem into a hierarchy of interrelated decision elements (criteria, decision alternatives). With the AHP, the objectives, criteria and alternatives are arranged in a hierarchical structure similar to a family tree. A hierarchy has at least three levels: overall goal of the problem at the top, multiple criteria that define alternatives in the middle, and decision alternatives at the bottom (Saaty, 1980). The second step is the comparison of the alternatives and the criteria. Once 
the problem has been decomposed and the hierarchy is constructed, prioritization procedure starts in order to determine the relative importance of the criteria within each level. The pairwise judgment starts from the second level and finishes in the lowest level, alternatives. In each level the criteria are compared pairwise according to their levels of influence and based on the specified criteria in the higher level (Saaty, 1980). In AHP multiple pairwise comparisons are based on a standardized comparison scale of nine levels (Table 1 ).

Table 1. Nine-point intensity of importance scale and its description

\begin{tabular}{ll}
\hline Definition & Intensity of importance \\
\hline Equally important & 1 \\
Moderately more important & 3 \\
Strongly more important & 5 \\
Very strongly more important & 7 \\
Extremely more important & 9 \\
Intermediate values & $2,4,6,8$ \\
\hline
\end{tabular}

AHP has been applied in many areas of decision making (Caputo et al., 2013). The basic steps of the method can be given (Saaty, 1990) as:

Step 1: Decompose of the entire problem into three levels: goal, judgment criteria and alternatives and making a Hierarchy diagram.

Step 2: Define the Score scale for each criterion.

Step 3: Based upon the scale defined, formation of a comparison matrix.

Step 4: The comparison matrix is then converted into a normalized matrix.

Suppose, $\mathrm{X}$ represents the comparison matrix:

$X=\left[x_{i j}\right]$; here $\boldsymbol{i}$ stands for equipments $(\boldsymbol{i}=1 \ldots \ldots . . . . n)$ and $\boldsymbol{j}$ stands for criteria $(\boldsymbol{j}=1 \ldots . . m)$ Then the normalized matrix from $\mathbf{X}$ can be obtained by:

$$
\mathrm{r}_{i j}=\frac{x_{i j}}{\sum_{i=1}^{n} x_{i j}}, \mathrm{j}=1,2, \ldots, \mathrm{m}
$$




\section{Step 5:}

Let $C=\left\{C_{j} \mid j=1,2 \ldots, n\right\}$ be the set of criteria. The result of the pairwise comparison on $n$ criteria can be summarized in an $(\boldsymbol{n} \times \boldsymbol{n})$ evaluation matrix $\boldsymbol{A}$ in which every element $\boldsymbol{a}_{i j}(\boldsymbol{i}, \boldsymbol{j}=\mathbf{1}, \mathbf{2} \ldots, \boldsymbol{n})$ is the quotient of weights of the criteria, as shown in Equation 1.

$$
A=\left[\begin{array}{llll}
a_{11} & a_{12} & \ldots & a_{1 n} \\
a_{21} & a_{22} & \ldots & a_{2 n} \\
\vdots & \vdots & \ddots & \vdots \\
a_{n 1} & a_{n 2} & \ldots & a_{n n}
\end{array}\right], \quad a_{i i}=1, a_{j i}=1 / a_{i j}, a_{i j} \neq 0
$$

where, $a_{i j}>0, a_{i j}=1 / a_{j i}, a_{i i}=1$, and $a_{i j}$ is the user defined rating of relative importance of criteria $i$ with respect to criterion $\boldsymbol{j}$. In case, $\boldsymbol{i}$ and $\boldsymbol{j}$ are of equal relative importance then $\boldsymbol{a}_{\boldsymbol{i j}}=\boldsymbol{a}_{\boldsymbol{j} \boldsymbol{i}}=\mathbf{1}$.

\begin{tabular}{c|cccc}
$K$ & $A_{1}$ & $A_{2}$ & $\cdots$ & $A_{n}$ \\
\hline$A_{1}$ & 1 & $a_{12}$ & $\cdots$ & $a_{1 n}$ \\
$A_{2}$ & $1 / a_{12}$ & 1 & $\cdots$ & $a_{2 n}$ \\
$\vdots$ & $\vdots$ & $\vdots$ & $\vdots$ & $\vdots$ \\
$A_{n}$ & $1 / a_{1 n}$ & $1 / a_{2 n}$ & $\cdots$ & 1
\end{tabular}

The values of relative rankings $\boldsymbol{a}_{i j}$ can be assumed as follows:

Criterion $\boldsymbol{i}$ and $\boldsymbol{j}$ are equally important: 1 .

Criterion $\boldsymbol{i}$ is slightly more important than criterion $\boldsymbol{j}$ :

3. Criterion $\boldsymbol{i}$ is significantly more important than criterion $\boldsymbol{j}$ :

5. Criterion $\boldsymbol{i}$ is strongly more important than criterion $\boldsymbol{j}$ :

7. Criterion $\boldsymbol{i}$ is extremely more important than criterion $\boldsymbol{j}$ :

9. values $2,4,6$, and 8 are used for intermediate numerical values. 
Step 6 and 7:

At the last steps, the mathematical process commences to normalize and find the relative weights for each matrix. The relative weights are given by the right eigenvector $(\boldsymbol{w})$ corresponding to the largest eigenvalue $\left(\boldsymbol{\lambda}_{\max }\right)$, as shown in Equation 2.

$A w=\lambda_{\max } w$

If the pairwise comparisons are completely consistent, the matrix $\boldsymbol{A}$ has rank 1 and $\boldsymbol{\lambda}_{\max }=\boldsymbol{n}$. In this case, weights can be obtained by normalizing any of the rows or columns of $\boldsymbol{A}$ (Saaty,1980).

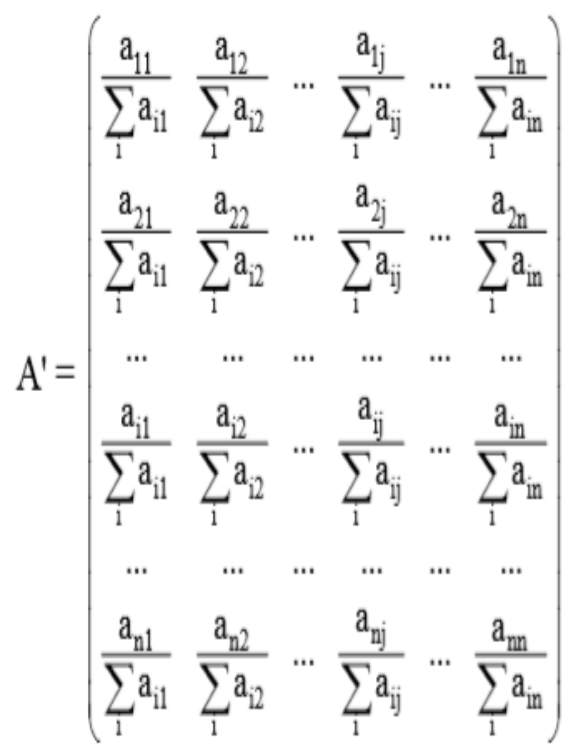

It should be noted that the quality of the output of the AHP is strictly related to the consistency of the pairwise comparison judgments. The consistency is defined by the relation between the entries of $\boldsymbol{A}: \boldsymbol{a}_{i j} \times \boldsymbol{a}_{j k}=\boldsymbol{a}_{i k}$. The consistency index $(\mathbf{C l})$ is shown in Equation 3.

$C l=\left(\lambda_{\max }-n\right) /(n-1)$

Then we calculated the final matrix $\boldsymbol{R}$ to represent the weight of different criteria of alternatives 


$$
\begin{aligned}
& \begin{array}{llllll}
\mathrm{W}_{1} & \mathrm{~W}_{2} & \ldots & \mathrm{W}_{\mathrm{j}} & \ldots & \mathrm{W}_{\mathrm{n}}
\end{array} \\
& \begin{array}{llllll}
\mathrm{C}_{1} & \mathrm{C}_{2} & \ldots & \mathrm{C}_{\mathrm{j}} & \ldots & \mathrm{C}_{\mathrm{n}}
\end{array}
\end{aligned}
$$

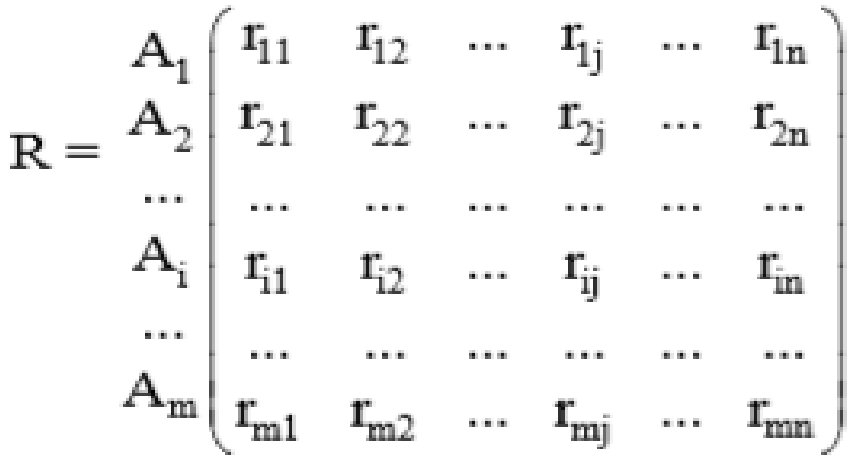

The final consistency index ratio (CIR), using which one can conclude whether the evaluations are sufficiently consistent, is calculated as the ratio of the $\mathrm{Cl}$ and the random index (RI), as shown in Equation 4.

$\mathrm{CIR}=\mathrm{Cl} / \mathrm{RI}$

where RI (from Table 2) is the Random Index.

Tabla 2. Random Consistency Indices (Saaty, 1980)

\begin{tabular}{ccccccccc}
$\boldsymbol{n}$ & 1 & 2 & 3 & 4 & 5 & 6 & 7 & 8 \\
$\boldsymbol{R I}$ & 0.00 & 0.00 & 0.58 & 0.90 & 1.12 & 1.24 & 1.32 & 1.41 \\
\hline $\boldsymbol{n}$ & 9 & 10 & 11 & 12 & 13 & 14 & 15 & \\
$\boldsymbol{R I}$ & 1.45 & 1.49 & 1.51 & 1.48 & 1.56 & 1.57 & 1.59 &
\end{tabular}

When the $\mathbf{C I R}$ is less than $\mathbf{0 . 1 0}$, we can take the Eigenvectors as the relative weights of the criteria for calculation of the weighted values for each of the alternatives. Ultimately, total weighted score and the corresponding rank would be found out.

The number 0.1 is the accepted upper limit for CIR. If the final consistency ratio exceeds this value, the evaluation procedure has to be repeated to improve consistency. The measurement of consistency can be used to evaluate the consistency of decision makers as well as the consistency of all the hierarchy (Saaty,1980). 


\section{Proposed AHP approach}

The AHP method, for the equipment PM problem consists of 3 basic stages: (1) Data, (2) AHP computations, (3) Decision making. In the first stage, alternative equipments and the criteria which will be used in their evaluation are determined and the decision hierarchy is formed. In the last step of the first stage, the decision hierarchy is approved by decision making expert. After the approval of decision hierarchy, criteria used in equipment PM are assigned weights using AHP in the second stage. In this phase, pairwise comparison matrices are formed to determine the criteria weights. The experts from decision making team make individual evaluations using the scale, provided in Table 1.

to determine the values of the elements of pairwise comparison matrices. Computing the pairwise comparison matrix on which there is a consensus is found. The weights of the criteria are calculated based on this final comparison matrix. In the last step of this phase, calculated weights of the criteria are approved by decision making experts.

Equipment PM elements priorities are found by the decision-making experts. After the approval of the element's functions, In the last step of the proposed procedure, the best elements equipment is selected according to the rankings of experts. Schematic representation of the proposed approach is presented in Figure 1.

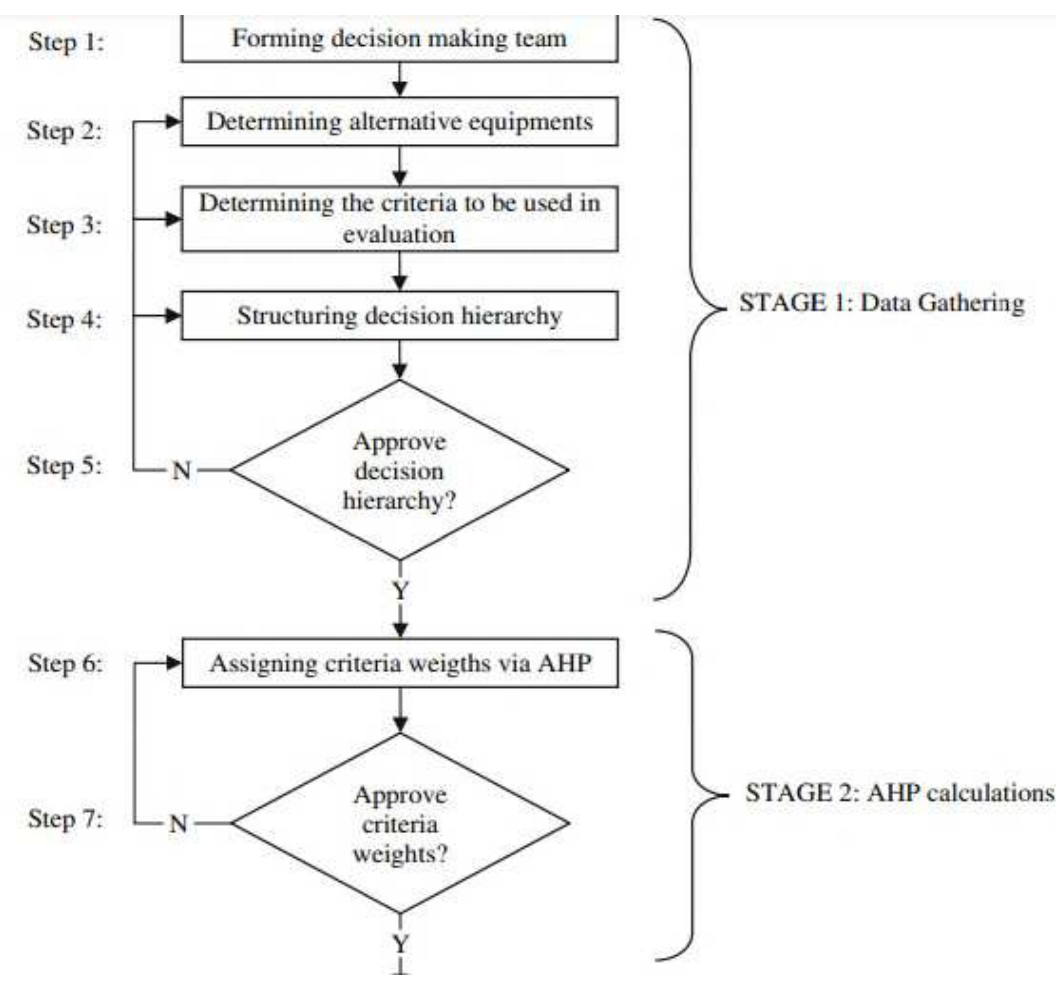

Figure 1. the proposed AHP approach 


\section{A theorical application of proposed approach}

To illustrate the proposed method, a hypothetical example has been presented using a 3D printer machine shown Figure 2. Suppose that an additive manufacturing company desires to select the most appropriate maintenance strategy that requires different alternatives to be assessed for a range of criteria. There is a variety of strategies in maintenance management systems depending on the type of applied industry in a company. These strategies can be categorized into two main groups of corrective and preventive ones. In corrective maintenance strategy, no maintenance activity is carried out until a failure occurs. Small profit margins along with ascending competition trend make the maintenance managers apply more reliable maintenance strategies. Conversely, preventive maintenance strategy is the strategy which is utilized before system failure to retain the system in the expected condition.

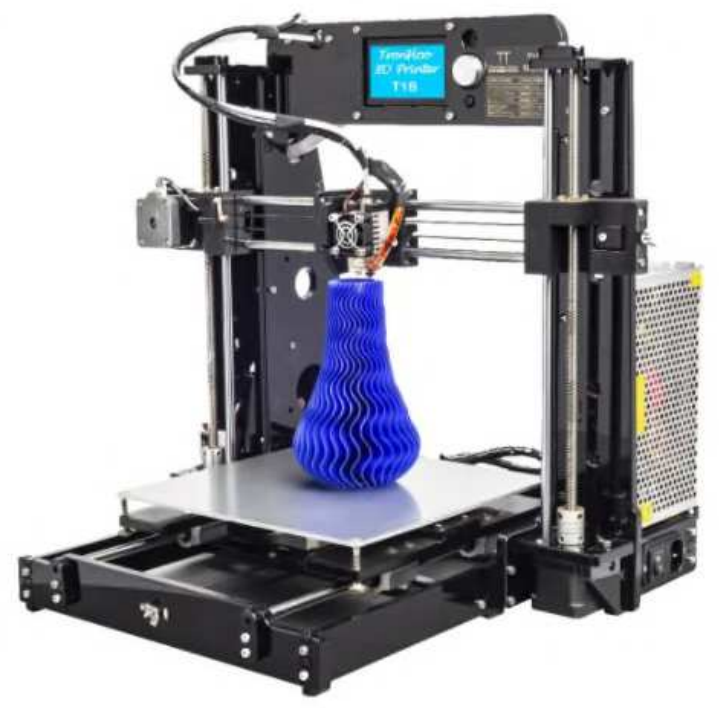

Figure 2. 3D machine printer theorical research proposed

\section{Methodology}

In this section, the MCDM method being used would be discussed. From the literature, it was found that TOPSIS, VIKOR, PROMETHEE, MOORA, ELECTRE, AHP etc. all were very popular in various types of multi-criteria decision-making processes. But we found AHP more suitable for our application as it is simple in use. Also, for any problem which can be decomposed in a hierarchical form, this is the best method. 


\section{The AHP method analysis}

Analytic Hierarchy Process (AHP) is a method to select one alternative from a given set of alternatives, where there are multiple decision criteria involved, and to rank available alternatives in a desirability order based on a rational framework of quantitative comparisons (Saaty, 1990). AHP is basically built on a solid yet simple theoretical foundation based on three basic principles (Marquez, 2006, Barba-Romero S. y Pomerol J. C. (1997):

1. Decomposition;

2. Comparative judgments; and

3. Hierarchy composition or synthesis of priorities.

AHP has been applied in many areas of decision making (Caputo et al., 2013). The basic steps of the method can be given (Saaty, 1990) as:

Step 1: Decompose of the entire problem into three levels: goal, judgment criteria (or simply criteria) and alternatives and making a hierarchy of the same. For our problem, Figure 3 gives the required information. Also, we have used different nomenclature of equipments in the diagram as given in the Table 3:

Table 3. Nomenclature of Equipments in AHP Diagram

\begin{tabular}{|c|c|}
\hline Name of system/ Alternatives & $\begin{array}{c}\text { Name of system/Alternatives in the AHP } \\
\text { Hierarchy Diagram }\end{array}$ \\
\hline Motor_X & Ele_1 \\
\hline Motor_Y & Ele_2 \\
\hline Motor_Z & Ele_3 \\
\hline Feeder material & Ele_4 \\
\hline Fan_1 & Ele_5 \\
\hline Nose feeder & Ele_6 \\
\hline Air pressure module & Ele_7 \\
\hline Temp_TC & Ele_8 \\
\hline Temp_Controller & Ele_9 \\
\hline Material & Ele_10 \\
\hline
\end{tabular}




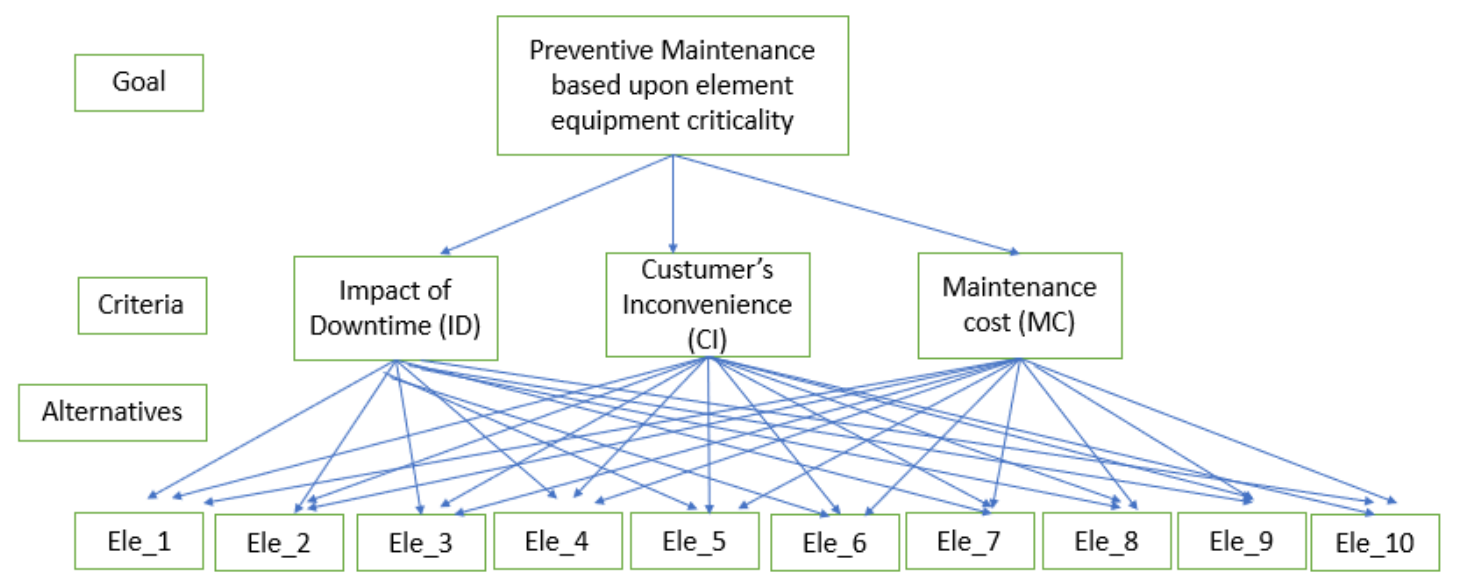

Figure 3. AHP Hierarchy Diagram of critical elements of Equipment.

Step 2: Define the Score scale for each criterion.

Step 3: Based upon the scale defined, formation of a comparison matrix.

Step 4: The comparison matrix is then converted into a normalized matrix.

Step 5: Define a pair-wise comparison of relative importance between the $\mathrm{n}$ rating criteria.

Step 6: and step 7: The pair-wise comparison matrix is checked for consistency and also the weight of different criteria is calculated.

\section{Description of the problem and analysis}

A lot of 3D printer machines are using in additive manufacturing factory. Some of these are very important from manufacturing point of view. In order to deploy the preventive maintenance of the critical elements is extremely important. Their criticality can be accessed on the following criteria:

1. Inconvenience caused to customers upon failure,

2. Impact on downtime when the equipment fails, and

3. Maintenance cost of the equipment.

The paper basically wants to capture all the possible scenarios whenever of the equipment fails. The data for PM will be theorical issues. But the analysis of the problem is very important and can't be ignored. Hence, to get this theorical data in a quantitative way. 


\section{Formation of Scale for Scoring of Different Criterion As discussed}

Three criteria for criticality analysis were considered; a 1-9 scale was used for scoring each of these from Table 1:

1. Impact of downtime when the equipment Fails (ID) A scale from 1-9 was used to capture all the probable values of the downtime impact. The Table 3 above is the scale table for the purpose.

2. Customer's Inconvenience Due to Failure ( $\mathrm{Cl})$ Any failure causes losses. When we have some equipment fail hence the customer may not be getting the finished product needed. It will cause inconvenience to the customer. We have formulated a scale based upon generation loss due to failure of an equipment to map the inconvenience caused to the customer Table 3 indicates it.

3. Maintenance Cost of the Equipment (MC) Whenever any equipment fails, it needs to be maintained to restore it at the desired level. This maintenance process carries some cost. Based upon average maintenance costs of equipment we have formulated a scale to map all possible maintenance costs in the scale (table 3).

\section{The Problem Analysis}

There are many functional parts equipments in 3D printer machine. We identified some important elements of equipment which directly impact of fails occurs. Criticality of these elements equipments was to be analyzed. Based upon the scoring formulated, the required score table is given below in table 4. For the analysis purposes we used AHP ranking shown in Table 1.

Table 4. Score Table or Comparison Matrix for the Equipments

\begin{tabular}{|c|c|c|c|}
\hline Name of system & $\begin{array}{c}\text { Impact of } \\
\text { downtime (ID) }\end{array}$ & $\begin{array}{c}\text { Custumer's } \\
\text { Inconvenience } \\
(\mathrm{Cl})\end{array}$ & $\begin{array}{c}\text { Maintenance } \\
\text { Cost (MC) }\end{array}$ \\
\hline Motor_X & 4 & 8 & 4 \\
\hline Motor_Y & 5 & 8 & 3 \\
\hline Motor_Z & 3 & 8 & 5 \\
\hline Feedermaterial & 2 & 4 & 2 \\
\hline Fan_1 & 6 & 4 & 2 \\
\hline Nose feeder & 8 & 7 & 9 \\
\hline Air pressure module & 5 & 9 & 2 \\
\hline Temp_TC & 9 & 7 & 2 \\
\hline Temp_Controller & 3 & 9 & 2 \\
\hline Electronic Controller & 4 & 4 & 2 \\
\hline
\end{tabular}


The method and the related algorithm have already been explained above.

The analysis is as follows:

Step 1: Decompose of the entire problem into three levels: goal, judgment criteria (or simply criteria) and alternatives and making a hierarchy of the same,

Step 2: Define the scale for each criterion: This has been defined as in table-6 for the three criteria.

Step 3: Based upon the scale defined formation of a comparison matrix: Table 3 gives the required comparison matrix of the alternatives.

Step 4: The comparison matrix is then converted into a normalized matrix;

This is given by Table 5 .

Tabla 5. Normalized Matrix Obtained from Comparison Matrix

\begin{tabular}{|c|c|c|c|}
\hline Name of system & $\begin{array}{c}\text { Impact of } \\
\text { downtime (ID) }\end{array}$ & $\begin{array}{c}\text { Custumer's } \\
\text { Inconvenience } \\
(\mathrm{Cl})\end{array}$ & $\begin{array}{c}\text { Maintenance } \\
\text { Cost (MC) }\end{array}$ \\
\hline Motor_X & 0.081 & 0.117 & 0.121 \\
\hline Motor_Y & 0.102 & 0.117 & 0.090 \\
\hline Motor_Z & 0.061 & 0.117 & 0.151 \\
\hline Feedermaterial & 0.040 & 0.058 & 0.060 \\
\hline Fan_1 & 0.122 & 0.058 & 0.060 \\
\hline Nose feeder & 0.163 & 0.102 & 0.272 \\
\hline Air pressure module & 0.102 & 0.132 & 0.060 \\
\hline Temp_TC & 0.183 & 0.102 & 0.060 \\
\hline Temp_Controller & 0.061 & 0.132 & 0.060 \\
\hline Electronic Controller & 0.081 & 0.058 & 0.060 \\
\hline
\end{tabular}

Step 5 and Step 6: Defining a pair-wise comparison matrix of the criteria and checking for their consistency:

The steps involved are explained with help of the actual pair-wise comparison matrix:

Step a: Write down the comparison matrix by Table 6 .

Table 6. Comparison Matrix

\begin{tabular}{|c|c|c|c|c|}
\hline & & ID & $\mathrm{Cl}$ & $\mathrm{MC}$ \\
\hline \multirow{3}{*}{$\mathrm{A}=$} & $\mathrm{ID}$ & 1 & 4 & 8 \\
\cline { 2 - 5 } & $\mathrm{Cl}$ & $1 / 4$ & 1 & 5 \\
\cline { 2 - 5 } & $\mathrm{MC}$ & $1 / 8$ & $1 / 5$ & 1 \\
\hline
\end{tabular}


Step b: Multiply together the entries in each row of the matrix, and then take $\boldsymbol{n}^{\text {th }}$ root of the product, where $\boldsymbol{n}$ is order of the matrix. Then the roots thus calculated are summed.

Now each of the root is normalized with the help of this sum to get a value called Eigenvector by Table 7.

Table 7. Eigenvector

\begin{tabular}{|c|c|c|c|c|c|}
\hline & ID & $\mathrm{Cl}$ & $\mathrm{MC}$ & 3rd. Root & Eigenvector \\
\hline $\mathrm{ID}$ & 1.000 & 4.000 & 8.000 & 3.175 & 0.699 \\
\hline $\mathrm{Cl}$ & 0.2500 & 1.000 & 5.000 & 1.077 & 0.237 \\
\hline $\mathrm{MC}$ & 0.1250 & 0.2000 & 1.000 & 0.292 & 0.064 \\
\hline & & & Total & 4.544 & 1.000 \\
\hline
\end{tabular}

Step c: We multiply each row of the comparison matrix by the Eigenvector column, just like matrix

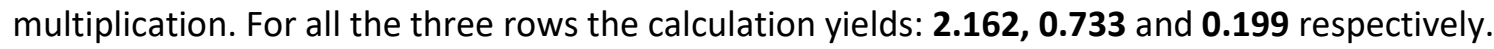

Step $\mathrm{d}$ : We divide the values in step-c by corresponding Eigenvectors to get the corresponding values of $\boldsymbol{\lambda}$. The average of the three values of $\boldsymbol{\lambda}$ gives us $\boldsymbol{\lambda}_{\max }$. Here $\boldsymbol{\lambda}_{\max }=\mathbf{3 . 0 9 4}$.

Step e: Consistency Ratio Index $(C I)=\left(\lambda_{\max }-n\right) /(n-1)=0.047$ for $n=3$

Step f: $\mathbf{C I} \boldsymbol{R}=\mathbf{C I} / \boldsymbol{R} \boldsymbol{I}=\mathbf{0 . 0 8 1}$. Saaty gave the random index $(\boldsymbol{R} \mathbf{I})$ for different orders of the judgment.

For $\boldsymbol{n = 3}$, this $\boldsymbol{R} \mathbf{l}=\mathbf{0 . 5 8}$ shown Tabla 2 . Here a $\mathbf{C I} \boldsymbol{R}$ value less than $\mathbf{0 . 1 0}$ says that our judgment is consistent.

Step 7: As the CIR is less than $\mathbf{0 . 1 0}$, we can take the Eigenvectors as the relative weights of the criteria for calculation of the weighted values for each of the alternatives to find out total weighted score and the corresponding rank. Table 8 gives the required ranks.

Table 8. Final Rank of PM equipment by AHP method

\begin{tabular}{|c|c|c|c|c|c|}
\hline Name of system & $\begin{array}{c}\text { Impact of } \\
\text { downtime } \\
(\text { ID) }\end{array}$ & $\begin{array}{c}\text { Custumer's } \\
\text { Inconvenience } \\
(\mathrm{CI})\end{array}$ & $\begin{array}{c}\text { Maintenance } \\
\text { Cost (MC) }\end{array}$ & $\begin{array}{c}\text { Weighted } \\
\text { score }\end{array}$ & Rank \\
\hline Motor_X & 0.081 & 0.117 & 0.121 & 0.092 & 6 \\
\hline Motor_Y & 0.102 & 0.117 & 0.090 & 0.105 & 4 \\
\hline Motor_Z & 0.061 & 0.117 & 0.151 & 0.080 & 7 \\
\hline Feeder material & 0.040 & 0.058 & 0.060 & 0.046 & 10 \\
\hline Fan_1 & 0.122 & 0.058 & 0.060 & 0.103 & 5 \\
\hline Nose feeder & 0.163 & 0.102 & 0.272 & 0.155 & 2 \\
\hline Air pressure module & 0.102 & 0.132 & 0.060 & 0.106 & 3 \\
\hline Temp_TC & 0.183 & 0.102 & 0.060 & 0.156 & 1 \\
\hline Temp_Controller & 0.061 & 0.132 & 0.060 & 0.078 & 8 \\
\hline Electronic Controller & 0.081 & 0.058 & 0.060 & 0.074 & 9 \\
\hline
\end{tabular}




\section{Result}

It was very interesting to look at the result. We all know that Temp_TC is one of the most important part of the 3D machine printer system. By AHP as well it was proved to be most critical as its rank was 1 with Weighted score is 0.156 from Table 8.

\section{Conclusion}

The best part in this type of analysis is that multiple criteria give a balanced view of the problem. It looks at the problem in totality by incorporating all the relevant criteria. Hence the analysis yields much better result. Probably, this type of analysis has been carried out for the first time for any 3D machine equipment using AHP method by Saaty. All the identified gaps have all been filled. 


\section{References}

Al-Najjar, B. and Alsyouf I. (2003), "Selecting the most efficient maintenance approach using fuzzy multiple criteria decisions making", International journal of production economics, 84(1), pp. 85-100

Alsyouf, I. (2004), "Cost Effective Maintenance for Competitive Advantages", Thesis for the Degree of Doctor of Philosophy (Terotechnology), School of Industrial Engineering, Växjö University Press.

Alsyouf, I. (2009), "Maintenance practices in Swedish industries: Survey results", International Journal of Production Economics, 121(2), pp. 133-149.

Atmani, A., \& Lashkari, R. S. (1998). A model of machine tool selection and operation allocation in flexible manufacturing system. International Journal of Production Research, 36, 1339-1349.

Ayag, Z., \& Ozdemir, R. G. (2006). A fuzzy AHP approach to evaluating machine tool alternatives. Journal of Intelligent Manufacturing, 17, 179-190.

Barba-Romero S. y Pomerol J. C. (1997). Decisiones multicriterio, fundamentos teóricos y utilización práctica. Colección de Economía. Servicio de Publicaciones de la Universidad de Alcalá de Henares.

Bashiri, M., Badri, H. and Hejazi, T. H. (2011). "Selecting optimum maintenance strategy by fuzzy interactive linear assignment method," Applied Mathematical Modelling, vol. 35, pp. 152-164.

Bertolini, M. and Bevilacqua, M. (2006). "A combined goal programming-AHP approach to maintenance selection problem, Reliability Engineering and System Safety, vol. 91(7), pp. 839-848.

Bevilacqua, M. and Braglia, M. (2000). "The analytic hierarchy process applied to maintenance strategy selection," Reliability Engineering and System Safety, vol. 70, pp. 71-83.

Brauers, WKM. (2004). Optimization methods for a stakeholder society. A revolution in economy thinking by multiobjective optimization. Kluwer Academic Publishers, Boston

Caputo, A.C., pelagagge, P.M. and Salini, P.; 2013; AHP- based methodology for selecting safety devices of industrial machinery; Safety Science Journal; 53; pp.201-218

Carazas, F.G. and Souza, G.F.M.; 2010; Risk-based decision-making method for maintenance policy selection of thermal power plant; Energy Journal; 35; pp.964-975.

Chan, F. T. S., Ip, R. W. L., \& Lau, H. (2001). Integration of expert system with analytic hierarchy process for the design of material handling equipment selection system. Journal of Materials Processing Technology, 116, 137-145.Chen, C. T. (2000). "Extensions of the TOPSIS for group decision-making under fuzzy environment," Fuzzy Sets and Systems, vol.114, pp. 1-9.

Chatterjee, P. and Chakraborty, S. (2012). Material selection using preferential ranking methods; Materials and Design; 35; pp.384-393

Chatterjee, P., Athawale, V.M. and Chakraborty, S.; 2011; Materials selection using complex proportional assessment and evaluation of mix data methods; Materials and Design; Vol.32; pp.851860. 
Chan, F. T. S., Ip, R. W. L., \& Lau, H. (2001). Integration of expert system with analytic hierarchy process for the design of material handling equipment selection system. Journal of Materials Processing Technology, 116, 137-145.

Chan, F. T. S., Kumar, N., Tiwari, M. K., Lau, H. C. W., \& Choy, K. L. (2007). Global supplier selection: a fuzzy-AHP approach. International Journal of Production Research. 110, 125-138.

Chen, M. A. (1999). Heuristic for solving manufacturing process and equipment selection problems. International Journal of Production Research, 37, 359-374

De Almeida, A. T., \& Bohoris, G. A. (1995). Decision theory in maintenance decision making. Journal of Quality in Maintenance Engineering, 1(1), 39-45.

Fouladgar, M. M., Yazdani-Chamzini, A., Lashgari, A., Zavadskas, E. K., \& Turskis, Z. (2012). MAINTENANCE STRATEGY SELECTION USING AHP AND COPRAS UNDER FUZZY ENVIRONMENT / PRIEŽIŪROS STRATEGIJOS PARINKIMAS TAIKANT AHP IR COPRAS METODUS NEAPIBRĖŽTOSE SITUACIJOSE. International Journal of Strategic Property Management, 16(1), 85104.

Fraser K., Hvolby H. H. and Tseng T. L. (2015), “Maintenance management models: a study of the published literature to identify empirical evidence", International Journal of Quality \& Reliability Management, 32(6), pp. 635-664.

Goh, H.H., Kok, B.C., Yeo, H.T., Lee, S.W. and Zin, A.A.M.; 2013; Combination of TOPSIS and AHP in load shedding scheme for large pulp mill electrical system; Electrical Power and Electrical Systems; 47; pp.198-204.

Handfield, R., Walton, S., Sroufe, R., Melnyk, S., 2002. Applying environmental criteria to supplier assessment: a study in the application of the analytical hierarchy process. European Journal Operational Research. 141, 70-87.

Ho W., Dey P. K. and Higson H. (2006). Multiple criteria decision-making techniques in higher education. International Journal of Educational Management, vol. 20, no. 5, pp. 319-337.

Huang, I.B., Keisler, J., Linkov, I., 2011. Multi-criteria decision analysis in environmental sciences: ten years of applications and trends. Science Total Environmental Journal. 409 (19), 3578-3594.

Kablan M. M. (2004). Decision support for energy conservation promotion: an analytic hierarchy process approach. Energy Policy, vol. 32, no. 10, pp. 1151-1158.

Kabir, G., Sadiq, R., Tesfamariam, S., 2013. A review of multi-criteria decision-making methods for infrastructure management. Structruture and Infrastructure Engineering, 1-35.

Kulak, O., Durmusoglu, M. B., \& Kahraman, C. (2005). Fuzzy multiattribute equipment selection based on information axiom. Journal of Materials Processing Technology, 169, 337-345.

Kutucuoglu, K. Y., Hamali, J., Irani, Z. and Sharp, J. M. (2001), "A framework for managing maintenance using performance measurement systems", International Journal of Operations \& Production Management, 21(1/2), pp. 173-195. 
Lee, S. K., Mogi, G., Lee, S. K. and Kim, J. W. (2011) Prioritizing the weights of hydrogen energy technologies in the sector of the hydrogen economy by using a fuzzy AHP approach, International Journal of Hydrogen Energy, 36(2), pp. 1897-1902.

Lerace, S. and Cavalieri, S. (2008). Maintenance strategy selection: a comparison between fuzzy logic and analytic hierarchy process. 9th IFAC Workshop on Intelligent Manufacturing Systems. Szczecin, Poland, pp. 228-233.

Lin, Z. C., \& Yang, C. B. (1996). Evaluation of machine selection by the AHP method. Journal of Materials Processing Technology, 57, 253-258

Linkov, I., Varghese, A., Jamil, S., Seager, T.P., Bridges, T., Kiker, G., 2004. Multicriteria decision analysis: a framework for structuring remedial decisions at contaminated sites. Comp. Risk Asses. Environ. Decision Anal., 15-54.

Mardani, A, Jusoh, A, and Zavadskas, E.K. (2015). Fuzzy multiple criteria decision-making techniques and applications - Two decades' review from 1994 to 2014. Expert Systems with Applications, 42(8):4126-4148, 2015.

Marquez, A.C. (2006). The Maintenance Management Framework (Models and Methods for Complex Systems Maintenance). Springer Series in Reliability Engineering.

Mechefske, C.K. and Wang, Z. (2003). "Using fuzzy linguistics to select optimum maintenance and condition monitoring strategies," Mechanical Systems and Signal Processing, vol. 17 (2), pp. 305316.

Mergias, I., Moustakas, K., Papadopoulos, A., \& Loizidou, M. (2007). Multi-criteria decision aid approach for the selection of the best compromise management scheme for ELVs: The case of Cyprus. Journal of Hazardous Materials, 147, 706-717.

Molenaers, A., Baets, H., Pintelon, L. and Waeyenbergh, G.; 2012; Criticality classification of spareparts: A case study; Int. J. Production Economics Journal; 140; pp.570-578.

Nelson, C. A. (1986). A scoring model for flexible manufacturing system project selection. European Journal of Operational Research, 24, 346-359.

Pariazar, M., Shahrabi, J., Zaeri, M.S. and Parhizi, S. (2008). "A combined approach for maintenance strategy selection," Journal of Applied Sciences, vol. 8 (23), pp. 4321-4329.

Pascual, R., Godoy, D. and Louit, D.M.; 2011; Throughput centered prioritization of machines in transfer lines; Reliability Engineering \& System Safety Journal; 96; pp. 1396-1401.

Peters, M. and Zelewski, S.; 2008; Pitfalls in the application of analytic hierarchy process to performance measurement; Management Decision Journal; Vol.46; No. 7; pp.1039-1051.

Petkov, D., Petkova, O., Andrew, T. and Nepal, T.; 2007; Mixing multiple criteria decisions making with soft systems thinking techniques for decision support in complex situations; Decision Support Systems; Vol.43; pp.1615-1629

Pohekar, S.D., Ramachandran, M., 2004. Application of multi-criteria decision making to sustainable energy planning-A review. Renew. Sustain. Energy Rev. 8 (4), 365-381. 
Oeltjenbruns, H., Kolarik, W. J., \& Kirschner, R. S. (1995). Strategic planning in manufacturing Systems-AHP application to an equipment replacement decision. International Journal of Production Economics, 38, 189-197.

Ong, S.K., Koh, T. H., \& Nee, A. Y. C. (2001). Assessing the environmental impact of materials processing techniques using an analytical hierarchy process method. Journal of Materials Processing Technology, 113, 424-431.

Salonen, A. (2011), "Strategic maintenance development in manufacturing industry", Doctoral Dissertation, School of Innovation, Design and Engineering, Mälardalen University.

Saaty T. L. (1980). The Analytic Hierarchy Process. McGraw-Hill: New York

Saaty T. L. (1990). How to Make a Decision. European Journal of Operational Research, V. 48, pp. 926.

Saaty T. L. (1994). Fundamentals of decision making and priority theory. Pittsburgh: RWS Publications

Saaty T. L. (2006). Rank from comparisons and from ratings in the analytic hierarchy/network processes. European Journal of Operational Research, V. 168, pp. 557-570.

Shafiee, M. (2015). Maintenance strategy selection problem: an MCDM overview. Journal of Quality in Maintenance Engineering, 21(4), 378-402.

Srikrishna, S., Yadava, G.S. and Rao, P.N.; 1996; Reliability centered maintenance applied to power plant auxiliaries; Journal of Quality in Maintenance Engineering; Vol.2; No.1; pp.3-14.

Standing, G., Flores, B., \& Olson, D. (2001). Understanding managerial preferences in selection equipment. Journal of Operation Management, 19, 23-37.

Sullivan, G. W., Mcdanold, T. N., \& Van Aken, E. M. (2002). Equipment replacement decisions and lean manufacturing. Robotics and Computer-Integrated Manufacturing Journal, 18, 255-265.

Tabucanon, M. T., Batanov, D. N., \& Verma, D. K. (1994). Intelligent decision support system (DSS) for the selection process of alternative machines for flexible manufacturing systems (FMS). Computers in Industry, 25, 131-143.

Turskis, Z. (2008). Multi-attribute contractors ranking method by applying ordering of feasible alternatives of solutions in terms of preferability technique. Technological and Economic Development of Economy 14(2), 224-239

Vincke, P. (1992). Multicriteria decision aid. Wiley.

Wang, L., Chu, J. and Wu, J. (2007). "Selection of optimum maintenance strategies based on a fuzzy analytic hierarchy process," International Journal of Production Economics, vol. 107, pp. 151-163.

$\mathrm{Wu}, \mathrm{W} . \mathrm{W}$. and Lee, Y.T.; 2007; Selecting knowledge management strategies by using the analytic network process; Expert Systems with Applications; Vol. 32; pp.841-847. 
Yang, T., Wen, Y.F. and Wang, F.F.; 2009; Evaluation of robustness of supply chain information sharing strategies using a hybrid Taguchi and multiple criteria decision-making method; International Journal of Production Economics.

Yurdakul, M. (2004). AHP as a strategic decision-making tool to justify machine tool selection. Journal of Materials Processing Technology, 146, 365-376.

Zeleny, M. (1982). Multiple criteria decision making. New York: McGraw-Hill.

Zhaoyang, T., Jianfeng, L., Zongzhi, W., Jianhu, Z. and Weifeng, H.; 2011; An evaluation of maintenance strategy using risk-based inspection; Safety Science; 49; pp.852-860. 